EDUR • Educação em Revista. 2021; 37:e25551 DOI: http://dx.doi.org/10.1590/0102-469825551

() (1) https://creativecommons.org/licenses/by/4.0/

ARTIGO

\title{
MODELOS DE PROFESSOR E ALUNO SUSTENTADOS EM DOCUMENTOS OFICIAIS: DOS PCNS À BNCC
}

\author{
CLÁUDIA VALENTINA ASSUMPÇÃO GALIAN ${ }^{1}$ \\ ORCID: https://orcid.org/0000-0002-1924-8802 \\ ÉMERSON DE PIETRI ${ }^{2}$ \\ ORCID: http://orcid.org/0000-0001-5060-9891 \\ LÚCIA HELENA SASSERON ${ }^{3}$ \\ ORCID: https://orcid.org/0000-0001-5657-9590
}

\begin{abstract}
RESUMO: Neste trabalho são apresentados resultados de pesquisa orientada pelo objetivo de conhecer os efeitos do discurso regulador sobre a recontextualização pedagógica de conhecimentos na elaboração de diretrizes curriculares oficiais. Com base em princípios de análise discursiva, caracterizam-se as permanências e mudanças expressas na Base Nacional Comum Curricular (BRASIL, 2017) em relação às concepções de ensino e de aprendizagem que fundamentaram anteriormente propostas curriculares no país, materializadas nos Parâmetros Curriculares Nacionais (BRASIL, 1997). A análise pauta-se na leitura e discussão de trechos destes dois documentos, com foco na caracterização de papéis que parecem ser atribuídos a professores e a estudantes. Os resultados evidenciam o reposicionamento, de um contexto histórico a outro, das funções projetadas para docentes e discentes nos processos de ensino e aprendizagem, de modo a desconsiderar-se a agentividade e a implicação dos sujeitos do trabalho pedagógico, reduzindo-se a relação didática à apropriação de um conjunto pré-estabelecido de conhecimentos. Embora não tenha sido a intenção do presente estudo, entendemos que esta investigação e seus resultados trazem contribuições às discussões sobre as normativas que passam a entrar em vigência em relação à formação de professores e também sobre a função da escola na formação de estudantes.
\end{abstract}

Palavras-chave: Currículo, Ensino Fundamental, BNCC, Discurso Regulador.

\section{TEACHER AND STUDENT MODELS SUSTAINED BY OFFICIAL DOCUMENTS: From PCN to BNCC}

\footnotetext{
${ }^{1}$ Universidade de São Paulo (USP). São Paulo (SP), Brasil. <claudiavalentina@usp.br>

${ }^{2}$ Universidade de São Paulo (USP). São Paulo (SP), Brasil. <pietri@usp.br>

${ }^{3}$ Universidade de São Paulo (USP). São Paulo (SP), Brasil. <sasseron@usp.br>
} 


\begin{abstract}
This paper presents the results of research oriented by the objective of knowing the effects of regulatory discourse on the pedagogical recontextualization of knowledge in the development of official curriculum guidelines. Based on principles of discourse analysis, the permanence and changes expressed in the Common National Curricular Base (BRASIL, 2017) are characterized in relation to the conceptions of teaching and learning that were the basis of previous curriculum proposals in the country, materialized in the National Curricular Parameters (BRASIL, 1997). The analysis is based on the reading and discussion of excerpts from these two documents, focusing on the characterization of roles that seem to be attributed to teachers and students. The results show the repositioning, from one historical context to another, of the roles projected for teachers and students in the teaching and learning processes, so as to disregard the agency and the implication of the subjects of the pedagogical work, reducing the didactic relationship to the appropriation of a pre-established set of knowledge. Although it was not the intention of this study, we understand that this investigation and its results bring contributions to the discussions about the norms that come into force in relation to teacher education and also about the function of the school in the formation of students.
\end{abstract}

Keywords: Curriculum, Elementary Education, National Common Curricular Base, Regulatory Discourse.

\title{
MODELOS DE PROFESOR Y ALUMNO SUSTENTADOS EN DOCUMENTOS OFICIALES: DEL PCN AL BNCC
}

RESÚMEN: Este artículo presenta los resultados de una investigación que tiene como objetivo conocer los efectos del discurso regulatorio en la recontextualización pedagógica del conocimiento. Con base en los principios del análisis discursivo, las permanencias y cambios expresados en la Base Curricular Común Nacional (BRASIL, 2017) se caracterizan en relación a los conceptos de enseñanza y aprendizaje que previamente sustentaban las propuestas curriculares en este país, sistematizadas en los Parámetros Curriculares Nacionales (BRASIL, 1997). El análisis se basa en discutir extractos de estos dos documentos curriculares, centrándose en la caracterización de roles que parecen atribuirse a docentes y estudiantes. Los resultados muestran el reposicionamiento, de un contexto histórico a otro, de las funciones a desempeñar por docentes y estudiantes en los procesos de enseñanza y aprendizaje, con el fin de desconocer su agentividad y implicación en el trabajo pedagógico. La relación didáctica se reduce entonces, en este contexto, a la apropiación de un conjunto de conocimientos preestablecidos. Si bien no fue el propósito de este trabajo, proponemos que esta investigación y sus resultados traigan contribuciones a las discusiones sobre las normas que entran en vigencia en relación a la formación del profesorado y también sobre el papel de la escuela en la formación de los alumnos.

Palabras clave: Currículo, Escuela Básica, Base Curricular Nacional Común, Discurso Regulatorio. 


\title{
INTRODUÇÃO
}

$\mathrm{Na}$ introdução da Base Nacional Comum Curricular (BNCC), bem como em materiais produzidos para a sua divulgação e legitimação, identifica-se a afirmação de que "a Base não é currículo". $\mathrm{Na}$ introdução do documento essa ideia é reforçada ao se definir que a BNCC e os currículos se complementam, de modo a "adequar as [suas] proposições [...] à realidade dos sistemas ou das redes de ensino e das instituições escolares, considerando o contexto e as características dos alunos" (BRASIL, 2017, p. 16). Essas adequações constituem o foco da investigação sobre a qual se baseia este artigo ${ }^{4}$. Nela, busca-se identificar e problematizar as escolhas realizadas por secretarias municipais de educação para estabelecerem o obrigatório alinhamento com as orientações curriculares centrais agora vigentes, segundo as perspectivas dos profissionais das redes de ensino no momento de composição de suas propostas curriculares. Nesse processo restarão marcas de algum grau de ruptura e/ou de continuidade com as propostas anteriores, que até então orientavam o trabalho escolar.

Entende-se que, como orientadores do currículo em desenvolvimento nas redes de ensino, os documentos de produção central são parte importante da criação de condições materiais e simbólicas de desenvolvimento do trabalho escolar. É nesse sentido que se focaliza neste texto aquilo que esses documentos delineiam como um modelo de professor, influenciando em alguma medida a produção mais recente de propostas curriculares por municípios brasileiros, bem como as ações para a sua formação inicial e continuada.

Como movimento inicial para a análise pretendida na pesquisa, considerou-se importante reconhecer as permanências e mudanças expressas na BNCC em relação ao que vinha orientando a produção de propostas curriculares no país - os Parâmetros Curriculares Nacionais (PCNs). Considerase que esse reconhecimento constituirá um suporte para reflexões sobre as pressões - novas ou não que recaem sobre os agentes recontextualizadores na elaboração das propostas curriculares.

Essa perspectiva é condizente com o que Barretto (2000) salienta, sustentando-se nas ideias de Ivor Goodson, ao justificar a escolha por estudar as prescrições curriculares. Para a autora, elas:

refletem [...] um ideário que permeia mais amplamente a sociedade através das suas instituições e das forças sociais que as animam, ideário esse que vai além da interpretação particular, que fazem os segmentos no poder, de certos princípios e pressupostos educacionais. Vêm, assim, tais orientações constituir, elas próprias, testemunhos que cristalizam, através de determinada versão pedagógica, certos valores socialmente compartilhados. (BARRETTO, 2000, p.7)

Muitos dos "testemunhos cristalizados" nos PCNs - e arrisca-se dizer, mesmo na BNCC -, remetem a políticas do ensino básico que compartilham uma mesma matriz, relacionada às mudanças sociopolíticas e econômicas mais amplas da década de 1990 (BARRETTTO, 2012, p. 740), genericamente denominadas de neoliberais. Tais marcas foram objeto de críticas - quando da publicação dos PCNs -, reunidas por Sampaio et al (2004 apud GALIAN, 2014) em quatro frentes, que ressaltam:

\begin{abstract}
1) seu potencial para fomentar a formação de identidades muito marcadas pelas chamadas da perspectiva neoliberal; 2) o viés psicologizante assumido na fundamentação teórica das escolhas curriculares, em detrimento dos aspectos sociológicos e políticos do debate; 3 ) o excessivo detalhamento das orientações; e 4) a insuficiência dos temas transversais para o tratamento e a promoção da crítica em relação aos debates em torno da diversidade e da pluralidade cultural. (GALIAN, 2014, p. 653-654. Grifo nosso)
\end{abstract}

Diante da BNCC, outras tantas críticas despontaram e a sua análise tem potencial para possibilitar a identificação de permanências e mudanças de um documento a outro. Como neste artigo têm centralidade os modelos de professor e de aluno, será sobre estes aspectos que nos deteremos.

Em Galian e Silva (2019), algumas das críticas à BNCC presentes em produções científicas recentes são reunidas em três frentes que focalizam:

\footnotetext{
${ }^{4}$ Esta pesquisa conta com financiamento da Fapesp (Auxílio Regular no 01329-2).
}

Educação em Revista|Belo Horizonte|v.37|e25551|2021 
a) O debate epistemológico acerca do conhecimento e da recusa à busca de um currículo nacional; b) A crítica política dos direcionamentos neoliberais e neoconservadores orientadores da BNCC; c) Os efeitos das definições constantes da Base sobre as práticas curriculares nas escolas e no âmbito da formação de professores. (GALIAN; SILVA, 2019, p. 526. Grifo nosso).

Se tomarmos os dois pontos em negrito nas citações imediatamente acima - o viés psicologizante assumido na fundamentação teórica dos PCNs, em detrimento dos aspectos sociológicos e políticos, e a preocupação com os efeitos das definições da BNCC sobre as práticas curriculares nas escolas e na formação de professores - nos aproximamos do tema deste artigo. O peso excessivo da visão psicologizante indicado em críticas aos PCNs era associado à centralidade crescente atribuída à aprendizagem e aos conhecimentos dos/as estudantes no desenvolvimento do currículo (SAMPAIO et al., 2004). Para além do apagamento das questões sociais e políticas envolvidas nos processos de aprendizagem - que tende a explicar dificuldades unicamente pelas características pessoais dos indivíduos - ressalta-se o risco de desvalorização do conteúdo do ensino em nome da relevância das culturas populares e das explicações já construídas pelos estudantes em seus grupos sociais de origem - que podem se tornar ao mesmo tempo ponto de partida e horizonte na abordagem dos conhecimentos escolares.

Por outro lado, a definição muito estrita de competências e habilidades na BNCC é alvo de críticas pela homogeneização das escolhas curriculares de escolas e professores que tende a fomentar. Diante de listas extensas de habilidades a serem trabalhadas em um ano escolar - agora com força de lei, inclusive, não mais se apresentando apenas como parâmetros -, reduz-se o espaço para as escolhas didáticas e curriculares que viabilizarão a criação de condições de aprendizagem para todos os estudantes - em outras palavras, contribui-se para obliterar o que é específico do trabalho do professor, o ensino (FRANGELLA, DIAS, 2018; MACIEL et al., 2017).

Nesse sentido, contrastando-se os objetivos e modos de implementação da BNCC, em relação aos objetivos e modos de implementação dos PCNs, observa-se uma hipertrofia nos movimentos pela centralização, unificação e imposição de currículos: de um momento histórico a outro, constitui-se uma rede de agentes privados, que, com sua atuação junto a instâncias públicas (secretarias, conselhos) e a agentes do mercado (corporações de mídia, de tecnologias digitais e editoras de livros didáticos), trabalha para que se imponha nacionalmente um currículo único que direcione a alocação dos investimentos públicos para a educação (CÁSSIO, 2018). Nesse processo, desqualificam-se, para sua submissão a interesses externos à escola, o trabalho docente e a função educativa para os estudantes e suas especificidades culturais, sociais e econômicas. A verticalização nos modos de distribuição social do conhecimento, estruturada em bases tecnicistas (SILVA, 2020), impõe um conjunto de conteúdos e de práticas pedagógicas em substituição aos saberes docentes e à produção de conhecimentos em contexto, o que leva à desvalorização das culturas escolares, à homogeneização curricular, como mencionado, e à impossibilidade da interpretação e da ação - o que se apresentava ainda que minimamente como margem para a agentividade docente nos PCNs se reduz, na BNCC, à aplicação de estratégias que garantam o acesso de quem deve aprender ao conteúdo a ser aprendido.

Este artigo se volta aos documentos curriculares federais para identificar pistas em relação ao que vem se mantendo, se acentuando ou mudando de forma mais radical nos discursos acerca do professor e do estudante, do ensino e da aprendizagem. Adicionalmente, questiona os desdobramentos dessas permanências e transformações na recontextualização que produzirá as propostas curriculares pelos entes federativos e na formação de identidades.

O conceito da recontextualização é central para a reflexão pretendida. Ele trata do processo que toma o conhecimento em seu campo de produção e o leva a compor o conhecimento escolar, por meio da ação de diferentes agentes recontextualizadores (BERNSTEIN, 1996, 2000). Focaliza-se no estudo uma dimensão do processo de recontextualização que marca o discurso pedagógico, ao delinear, em alguma medida, a transformação do conhecimento a ser transmitido.

O uso do termo currículo, neste estudo, inspira-se também na teoria de Bernstein, que o associa ao "conhecimento que é recontextualizado dos campos disciplinares e codificado e organizado no conhecimento escolar a ser ensinado" (HOADLEY, 2018, p. 81). Para Bernstein, o discurso pedagógico é o que resulta da inserção de um discurso instrucional, ligado às disciplinas, em uma base 
representada pelo discurso regulador. $\mathrm{O}$ discurso regulador condensa as diferentes posições presentes num cenário específico em torno da defesa de pedagogias centradas no professor e pedagogias centradas no aluno, assim como a necessidade de aceitação das formas culturais existentes (HOADLEY, 2018, p. 26). Em outras palavras, o discurso regulador associa e expressa acordos temporários com base em considerações políticas, sociais, pedagógicas e psicológicas presentes em um determinado contexto. Dessa forma, o discurso regulador estabelece modelos de professor e de aluno, bem como legitima determinadas formas de relações entre eles, segundo normas estabelecidas nos debates entre interesses de ordens distintas, desde os que se fundam no campo educacional até os que encontram suporte nos interesses sociais, econômicos e políticos mais amplos.

Para a análise ora desenvolvida, tem relevância ainda a visão de Bernstein acerca das reformas curriculares $^{5}$. Para o autor, elas

emergem da luta entre grupos para fazer das suas perspectivas (e focos) políticas e práticas do Estado. Assim, as perspectivas e focos desse discurso oficial [materializado nos documentos curriculares e em ações a eles articuladas] pretendem construir em professores e estudantes uma disposição moral, uma motivação e aspiração particulares, expressas em práticas e performances particulares (BERNSTEIN, 2000, p. 65. Tradução nossa).

Partilhando esse ponto de vista, Hoadley (2018) levantou estudos que analisaram as reformas curriculares levadas a cabo em países em desenvolvimento entre o final dos anos 1990 e a primeira década dos anos 2000, chegando a um conjunto de características que marcaram o discurso oficial em todas elas - que guardam alguma correlação com o que se deu no contexto brasileiro no mesmo período. A autora indica:

Como resultado de persistentes maus resultados [em grandes avaliações], tem havido extensivos debates políticos e esforços reformistas em torno do currículo e da pedagogia, vistos como chaves para a qualidade da educação (e, nesses países em desenvolvimento especialmente, para melhorar o capital humano). [...]. Em muitos países, mudanças curriculares e metodológicas foram propostas, e de uma forma geral voltavam-se à promoção de uma pedagogia centrada no aluno [...]. A intenção em quase todos os casos foi substituir um currículo centrado no conhecimento. Nessa virada neoliberal, o currículo tinha que se tornar "mais transparente e responsivo às necessidades dos empregadores e dos aprendizes” (Allais, 2014, p. xvii). O estudante nesses tipos de currículo era frequentemente representado como um consumidor, capaz de fazer escolhas, transferir e acumular aprendizagens. O conhecimento foi atomizado e mercantilizado e as escolhas maximizadas (HOADLEY, 2018, p. 13-14. Traducão nossa).

Outras características semelhantes entre as reformas analisadas por esses estudos consistem: na ênfase sobre inclusão de valores, atitudes e habilidades em oposição ao conhecimento estrito das disciplinas escolares; na prevalência do conhecimento local e das explicações já desenvolvidas pelos estudantes, e no movimento em direção a um currículo integrado (HOADLEY, 2018, p. 14). É possível reconhecer, nesse quadro desenhado pela autora, semelhanças com o que começa a se configurar como discurso oficial nos PCNs (BARRETTO, 2012) e que parece se aprofundar na BNCC - como a força das competências e habilidades - inclusive as denominadas competências socioemocionais -, e a relação instrumental com o conhecimento. Nesse processo de caráter utilitarista, a educação não responde às necessidade formativas, às relações com o pensamento, mas responde ao objetivo da qualificação valorizada pela empresa capitalista, do aprender a aprender, de modo a tornar-se competente para a solução de questões circunstanciais (MANFRÉ, 2020).

Responde, nesse sentido, às agendas dos interesses econômicos mundiais que buscam não apenas orientar os processos educacionais para os interesses do capital, mas também mercantilizar a própria educação, de modo que seja gerenciada, tanto em relação aos métodos de ensino, quanto em relação à produção e distribuição dos materiais didáticos, por empresas com fins lucrativos (HYPOLITO, 2019). Branco et al (2019) complementam essa perspectiva, afirmando que, com a ênfase

\footnotetext{
${ }^{5}$ Muitas pesquisas sobre currículo e reformas curriculares vêm sendo desenvolvidas em diversos países, e também no Brasil, tomando como referência teórica principal os escritos de Basil Bernstein. Dentre elas, destacam-se: Neves e Morais (2010), Morais, Neves e Ferreira (2019), Hoadley (2018), Weelahan (2010), no âmbito internacional, e Sampaio (1998), Mainardes e Stremel (2010), Coelho (2017) e Galian e Stefenon (2018), no contexto brasileiro, entre muitos outros.
} 
da BNCC aos métodos e procedimentos em detrimento da abordagem de conteúdos científicos, artísticos e filosóficos, expõe-se a possibilidade de negligenciar a formação crítica dos estudantes e, com isso, a emancipação do cidadão.

A homogeneização do currículo e a padronização das práticas pedagógicas encontram suas finalidades nas avaliações externas, nos programas de metas, nas políticas de incentivo à concorrência e nas ações de reponsabilização individual, de gestores, professores e estudantes, quanto aos resultados de desempenho e eficiência (SOUSA; ARAGÃO, 2018). Cabe questionar o efeito desse aprofundamento sobre os modelos de professor e aluno fomentados pelos documentos curriculares.

Do ponto de vista metodológico, a pesquisa em andamento, de natureza qualitativa, faz uso do procedimento de análise documental, tem como fontes a BNCC e propostas curriculares de três municípios do estado de São Paulo. A análise documental se desenvolve em dois âmbitos: 1. Geral - que pretende identificar os elementos que permitiriam caracterizar o discurso regulador (BERNSTEIN, 2000), referentes ao modelo de professor e de aluno, às teorias de instrução e aos princípios de ordem moral assumidos nos documentos curriculares (HOADLEY, 2018) -, e 2. Específico - que focaliza o discurso instrucional (BERNSTEIN, 2000), envolvendo a identificação de ênfases e omissões relativas aos conteúdos centrais de dois componentes curriculares: Língua Portuguesa e Ciências Naturais. O trabalho no primeiro âmbito é o que se apresenta neste artigo, que analisa a constituição do discurso regulador nos PCNs e na BNCC.

A produção dos dados de análise se fundamenta em referenciais teórico-metodológicos segundo os quais os discursos se constituem em relações interdiscursivas, que compreendem processos de partilhas, de recusas, de negações e de denegações, com base em que os discursos em concorrência se delimitam reciprocamente e estabelecem seus modos de funcionamento e suas identidades (MAINGUENEAU, 2005).

O analista do discurso opera de modo a recortar, num campo discursivo que compreende vários discursos em concorrência, um espaço discursivo que integre os discursos específicos que se busca analisar num dado momento e com determinado objetivo (MAINGUENEAU, 1997; 2005). A análise dos processos interdiscursivos em sua materialidade linguística possibilita caracterizar as bases semânticas dos discursos observados, evidenciando-se os valores que nesses discursos são atribuídos a temas, objetos e conceitos, bem como aos sujeitos que deles participam e suas posições.

$\mathrm{Na}$ presente investigação, o recorte interdiscursivo para análise recobre os discursos curriculares para a educação básica produzidos em esferas oficiais federais, no Brasil, em dois momentos históricos específicos, antes mencionados. Busca-se caracterizar, com a análise dos dados, os modos de constituição do discurso regulador nos contextos observados, contrastando-os quanto às representações políticas, sociais, pedagógicas e psicológicas que se materializam em cada um dos processos discursivos analisados, com os modelos de professor e de aluno, e as formas de relações entre eles, que são apresentadas como legítimas, em contraposição, explícita ou não, às que definem como não satisfatórias ou não pertinentes.

\section{RESULTADOS E DISCUSSÃO}

As diferentes funções atribuídas ao professor nos PCNs e na BNCC podem ser observadas nos recursos linguísticos e discursivos empregados para representar o que deva ser o trabalho docente segundo o discurso regulador constituído em um contexto sócio-histórico e outro - a segunda metade da década de 1990, no caso do primeiro, e o período entre 2015 e 2017, no caso da BNCC (texto introdutório). Dado o caráter dos documentos, prevalece em ambos o tom prescritivo quanto ao que se define que seja o trabalho docente, mas a posição ocupada pelo professor em relação a seu trabalho se altera substancialmente de um a outro.

Nos PCNs, o professor ocupa posição decisória no processo curricular, de modo a estabelecer não apenas métodos de ensino (como ensinar e avaliar), mas também os conteúdos a serem ensinados, e seu tempo (o que e quando ensinar):

O professor deve ter propostas claras sobre o que, quando e como ensinar e avaliar, a fim de possibilitar o planejamento de atividades de ensino para a aprendizagem de maneira adequada e Educação em Revista|Belo Horizonte|v.37|e25551|2021 
coerente com seus objetivos. É a partir dessas determinações que o professor elabora a programação diária de sala de aula e organiza sua intervenção de maneira a propor situações de aprendizagem ajustadas às capacidades cognitivas dos alunos. Em síntese, não é a aprendizagem que deve se ajustar ao ensino, mas sim o ensino que deve potencializar a aprendizagem (BRASIL, 1997, p. 39)

O ensino não pode estar limitado ao estabelecimento de um padrão de intervenção homogêneo e idêntico para todos os alunos (BRASIL, 1997, p. 61)

O professor é representado nos PCNs como aquele que planeja, organiza, intervém e propõe, em seu trabalho docente, de modo a garantir que a aprendizagem se realize de modo satisfatório. O trabalho docente nesse documento é posicionado como uma função do processo de aprendizagem, devendo responder hierarquicamente a ela, afirmando-se como atributo do professor decidir como desenvolver seu trabalho pedagógico.

$\mathrm{Na} \mathrm{BNCC}$, o professor não é representado como o responsável pelas decisões sobre o que, quando e como ensinar, pois a relação pedagógica não é observada como atributo dos sujeitos da docência e da aprendizagem, mas objetificada nos conteúdos a serem distribuídos: o professor contextualiza; não produz, mas identifica estratégias, para apresentar, representar, exemplificar, conectar e tornar significativo. Não participa, assim, das decisões curriculares e tem função instrumental nas atividades escolares:

[Cabe ao professor] contextualizar os conteúdos dos componentes curriculares, identificando estratégias para apresentá-los, representá-los, exemplificá-los, conectá-los e torná-los significativos, com base na realidade do lugar e do tempo nos quais as aprendizagens estão situadas (BRASIL, 2017, p. 12)

Projeta-se assim uma docência sem docente, e aprendizagens sem sujeitos que aprendam: estas são também objetificadas, e dispostas em determinados tempos e lugares, os contextos nos quais as aprendizagens estão situadas, num movimento de simplificação - como se ao ligar a docência e a aprendizagem aos elementos mais imediatos do contexto em que se vive, apenas, já se respondesse à necessidade de considerar as condições muito desiguais nas quais esses processos se desenvolvem.

Opõe-se essa perspectiva estabelecida na BNCC ao modo como é projetada a aprendizagem nos PCNs, considerada um atributo dos sujeitos que aprendem em função de suas particularidades, o que produz efeitos sobre os processos de definição dos conteúdos de ensino e de seu tratamento didático:

A concepcãa da área evidencia a natureza dos conteúdos tratados, definindo claramente o corpo de conhecimentos e o objeto de aprendizagem, favorecendo aos alunos a construção de representações sobre o que estudam. Essa caracterização da área é importante também para que os professores possam se situar dentro de um conjunto definido e conceitualizado de conhecimentos que pretendam que seus alunos aprendam, condição necessária para proceder a encaminhamentos que auxiliem as aprendizagens com sucesso (BRASIL, 1997, p. 44)

A definição de conteúdos nos Parâmetros Curriculares Nacionais é uma referência suficientemente aberta para técnicos e professores analisarem, refletirem e tomarem decisões, resultando em ampliaç,ões ou reduções de certos aspectos, em função das necessidades de aprendizagem de seus alunos (BRASIL, 1997, p. 54)

O professor é representado como quem dispõe de conhecimentos com base nos quais organiza e desenvolve suas práticas pedagógicas. Professor e técnicos analisam, refletem e decidem. Essa atribuição é esvaziada na BNCC, cabendo ao professor:

Selecionar e aplicar metodologias e estratégias didático-pedagógicas diversificadas, recorrendo a ritmos diferenciados e a conteúdos complementares, se necessário, para trabalhar com as necessidades de diferentes grupos de alunos, suas famílias e cultura de origem, suas comunidades, seus grupos de socialização etc. [...] Selecionar, produzir, aplicar e avaliar recursos didáticos e tecnológicos para apoiar o processo de ensinar e aprender (BRASIL, 2017, p. 12) 
Enfatizam-se as diferenças entre os sujeitos e as culturas, como elementos geradores de práticas diversificadas, cabendo ao professor escolhas metodológicas e sua aplicação, buscando, eventualmente, selecionar conteúdos complementares, se necessário, havendo assim pouco espaço para se afastar do que é prescrito no documento.

Isso permite entender a concepção de conteúdo assumida pela BNCC como restrita aos conceitos de uma determinada área, não incorporando as normas e práticas, que constituem epistemicamente um dado campo, como conteúdo a ser desenvolvido em aula.

$\mathrm{Na} \mathrm{BNCC}$, essa injunção dos sujeitos da relação pedagógica ao que esteja estritamente prescrito no documento curricular, delineada no modelo de professor definido no discurso regulador, não enfatiza qualquer possibilidade de ação criadora ou produtiva docente, mas também discente: na passagem em análise, não se qualifica pedagógica ou didaticamente o termo "necessidades", de modo que ele não esteja claramente associado a ações de ensino ou de aprendizagem. Esvazia-se, assim, a posição dos sujeitos nas relações didático-pedagógicas. Esse esvaziamento produz efeitos sobre os sentidos do trabalho pedagógico e as funções atribuídas aos sujeitos na construção desses sentidos.

A necessidade de produção significativa da relação didático-pedagógico como uma atribuição docente é expressa explicitamente como um dado do discurso regulador materializado nos PCNs:

[Ao professor] cabe apresentar os conteúdos e atividades de aprendizagem de forma que os alunos compreendam o porquêe o para que do que aprendem, e assim desenvolvam expectativas positivas em relação à aprendizagem e sintam-se motivados para o trabalho escolar. Para tanto, é preciso considerar que nem todas as pessoas têm os mesmos interesses ou habilidades, nem aprendem da mesma maneira, o que muitas vezes exige uma atenção especial por parte do professor a um ou outro aluno, para que todos possam se integrar no processo de aprender. A partir do reconhecimento das diferenças existentes entre pessoas, fruto do processo de socialização e do desenvolvimento individual, será possível conduzir um ensino pautado em aprendizados que sirvam a novos aprendizados" (BRASIL, 1997 p. 48)

Nos PCNs, a prática pedagógica, ao ser definida pelo processo de aprendizagem, posicionase como função das especificidades dos sujeitos discentes, e, assim, estabelece-se uma relação necessária entre professor e aluno para a construção de relações didáticas específicas e diversificadas, porque particulares, circunstanciais, específicas.

Na BNCC, a motivação e o engajamento dos alunos dependem das situações colocadas em prática pelo professor sem que se observem as particularidades e as condições para construção de sentido para o que se aprende: [Cabe ao professor] conceber e pôr em prática situações e procedimentos para motivar e engajar os alunos nas aprendizagens (BRASIL, 2017, p. 12). O professor é o responsável pela motivação e o engajamento do estudante na relação com o conhecimento escolar, nessa perspectiva, mas não porque o apoia na construção de sentido para o que aprende - em outras palavras, não porque ensina -, mas porque busca, como um técnico, estratégias inovadoras e estimulantes para cumprir com o que está determinado nas prescrições. Daí decorre, ainda, uma visão muito específica do que se define como a necessária

revisão da formação inicial e continuada dos professores para alinhá-las à BNCC. A ação nacional será crucial nessa iniciativa, já que se trata da esfera que responde pela regulação do ensino superior, nível no qual se prepara grande parte desses profissionais. Diante das evidências sobre o peso do professor na determinação do desempenho do aluno e da escola de educação básica, essa é uma condição indispensável para a implementação da BNCC (BRASIL, 2017, p. 15)

O “alinhamento" à BNCC, em coerência com o modelo de professor assumido, deverá tratar de enfatizar a importância dessas estratégias inovadoras e estimulantes, muito mais do que fomentar o que historicamente se reconhece no campo da educação como crucial para formar um professor: o equilíbrio entre os aspectos teóricos e práticos do trabalho docente. Para esse modelo de professor, certamente o âmbito prático da formação inicial e continuada se mostra muito mais relevante do que as reflexões teóricas embasadas nas ciências da educação. 
Destaca-se, ainda, no último excerto da BNCC, acima, a importância do professor na determinação do desempenho do aluno e da escola, mas não se considera a construção de sentido para o contexto de ensino e de aprendizagem. Observa-se, mais uma vez, que a exclusão do professor de sua função docente se reflete na exclusão do aluno de sua função discente: o aluno é posicionado externamente ao processo de aprendizagem - ele não é representado como aquele que aprende, mas como aquele que deve se engajar na aprendizagem. Na BNCC, aprendizagem não é ação de um sujeito, mas um adjunto adverbial em relação ao qual um determinado sujeito deve se posicionar. Ao se destituírem os sujeitos da relação pedagógica de suas funções de ensino e de aprendizagem, a motivação e o engajamento não se fundamentam em processos significativos de ensino, mas em elementos sociais e emocionais inespecíficos.

Com relação aos alunos, verifica-se que já nos PCNs se explicitava uma preocupação com a formação do profissional que será necessário no cenário de mudanças aceleradas em que vivemos. É o que destaca o trecho a seguir:

Não basta visar à capacitação dos estudantes para futuras habilitações em termos das especializações tradicionais, mas antes trata-se de ter em vista a formação dos estudantes em termos de sua capacitação para a aquisição e o desenvolvimento de novas competências, em função de novos saberes que se produzem e demandam um novo tipo de profissional (BRASIL, 1997, p. 28)

Mas, se a preocupação com a formação de alguém que deverá se tornar o profissional para um futuro de difícil projeção mantém-se na BNCC, algo diferente surge quando o documento remete ao sujeito que deve desenvolver "as competências que se contrapõem à concepção de conhecimento desinteressado e erudito entendido como fim em si mesmo" (BRASIL, 2017, p. 17, grifo nosso). Surge, nesse excerto, uma posição de contrariedade em relação ao que se denomina de "conhecimento desinteressado e erudito como fim em si mesmo". Mesmo que a noção de competência já estivesse em cena nos PCNs e que ela se refira à mobilização de conhecimentos diversos para resolver problemas mais imediatos, é interessante reconhecer que este documento não manifestava o mesmo posicionamento em relação aos conhecimentos de base acadêmica ou especializados, ligados centralmente à própria função social da escola: "as escolas brasileiras, [...], precisam possibilitar o cultivo dos bens culturais e sociais, considerando as expectativas e as necessidades dos alunos, dos pais, dos membros da comunidade, dos professores, enfim, dos envolvidos diretamente no processo educativo" (BRASIL, 1997, p. 35).

É o que também se percebe quando os PCNs defendem a formação de

cidadãos capazes de interferir criticamente na realidade para transformá-la, [que desenvolvam] capacidades que possibilitem adaptações às complexas condições e alternativas de trabalho que temos hoje e a lidar com a rapidez na produção e na circulação de novos conhecimentos e informações, que têm sido avassaladores e crescentes (BRASIL, 1997, p. 34)

Ainda que a BNCC remeta ao conceito de autonomia ao enfatizar a capacidade de fazer escolhas com base em reflexões críticas, a ideia de que tudo o que se aprende na escola deve "servir" na vida dos estudantes pode apontar para uma relação instrumental com o conhecimento, pouco reflexiva, que permitiria, no limite, entender que qualquer coisa que não tenha utilidade na vida "imediata" do aluno, ou que não responda ao que o futuro talvez lhes demande, é inútil e não merece o esforço para ser ensinado e aprendido.

Um outro aspecto que merece ser destacado em relação à autonomia dialoga diretamente com características do trabalho docente que percebemos serem assumidas pela BNCC. Assumida na relação direta com a utilidade dos conhecimentos apresentados aos estudantes, a própria ideia de autonomia surge problemática, pois desconsidera a possibilidade de que os conhecimentos apresentados não sejam incorporados às práticas dos sujeitos.

Mais além: pensada como uma capacidade que é trabalhada em aula, pelo currículo, a autonomia surge também pela atuação do professor que, ao apresentar as práticas que constituem epistemicamente sua área de conhecimento, permite aos alunos o contato com o conhecimento como uma prática social. Mas se ao professor, conforme o texto da BNCC, cabe apenas a tarefa de selecionar 
recursos metodológicos, talvez a abordagem dos conteúdos ocorra de modo tradicional e, por isso, como um empreendimento privado.

Nos excertos dos PCNs são realçados o caráter de construção social dos conhecimentos, bem como a reconstrução dos saberes que se dá no processo de ensino e de aprendizagem, que têm nos professores e alunos em interação os parceiros na jornada do desenvolvimento escolar. Ao tratar desses aspectos - ou, ao silenciar sobre eles - a BNCC opta por falar em "conhecimento curricular contextualizado na realidade local, social e individual da escola e do seu alunado" (BRASIL, 2017, p. 9), para realçar o que deve fazer o professor (contextualizar o conhecimento). Trata-se de "contextualizar os conteúdos dos componentes curriculares, identificando estratégias para apresentá-los, representá-los, exemplificá-los, conectá-los e torná-los significativos, com base na realidade do lugar e do tempo nos quais as aprendizagens estão situadas" (BRASIL, 2017, p. 12). Não há nada a ser feito pelo estudante aqui: o professor, essencialmente por meio das estratégias que desenvolve para ensinar o que o documento define como aprendizagens essenciais, é considerado responsável até mesmo por tornar os conteúdos significativos para seus alunos. Pergunta-se: não seria propriamente responsabilidade do professor buscar garantir as condições para que os estudantes confiram significado ao que aprendem? $\mathrm{O}$ que caberia ao estudante, então? Faz-se importante trazer aqui, a esse respeito, o que afirma Charlot (2008):

Só pode aprender quem desenvolve uma atividade intelectual para isso e, portanto, ninguém pode aprender no lugar do outro. Às vezes, quando um aluno não entende as explicações da professora, esta gostaria de poder entrar no seu cérebro para fazer o trabalho. Mas não pode: por mais semelhantes que sejam os seres humanos, são também singulares e, logo, diferentes. Quem aprende é o aluno. Se não quiser, recusando-se a entrar na atividade intelectual, não aprenderá, seja qual for o método pedagógico da professora. (CHARLOT, 2008, p. 23)

Ao professor cabe também, segundo a BNCC, estar atento à diversidade dos alunos e aos seus interesses e necessidades: "a diversidade é inerente ao conjunto dos alunos, inclusive no que diz respeito às experiências que trazem para o ambiente escolar e aos modos como aprendem" (BRASIL, 2017, p. 11). Uma vez que a responsabilidade pela motivação, o interesse e mesmo o significado para o que aprendem os estudantes é atribuída ao professor, parece restar ao aluno uma posição muito passiva na relação com o conhecimento: ele traz suas experiências e necessidades para a escola, o professor faz a leitura desses aspectos e encontra estratégias para garantir as aprendizagens definidas na BNCC. Ainda assim, o documento fala em protagonismo do aluno, embora pareça algo que não está em sintonia com o que se aponta como expectativa sobre o trabalho do professor:

A superacão da fragmentação radicalmente disciplinar do conhecimento, o estímulo à sua aplicação na vida real, o protagonismo do aluno em sua aprendizagem e a importância do contexto para dar sentido ao que se aprende são alguns dos princípios subjacentes à BNCC (BRASIL, 2017, p. 17)

Outro aspecto de continuidade entre os dois documentos é a não centralidade do conhecimento, secundarizado em importância quando frente às capacidades (nos PCNs) e às competências (na BNCC). Os excertos abaixo evidenciam isso:

[Os PCNs], [...], adotam como eixo o desenvolvimento de capacidades do aluno, processo em que os conteúdos curriculares atuam não como fins em si mesmos, mas como meios para a aquisição e desenvolvimento dessas capacidades (BRASIL, 1997, p. 33).

[Os] conteúdos curriculares estão a serviç,o do desenvolvimento de competências (BRASIL, 2017, p. 9)

Esse é um aspecto que já está presente no cenário educacional brasileiro há algum tempo, assumindo o caráter de objetivos educacionais que pretendem ultrapassar os objetivos cognitivos, englobando outros aspectos da formação dos sujeitos, e chegando à noção de competência, que igualmente desloca os conteúdos intelectuais do centro das discussões curriculares, em nome do maior envolvimento dos estudantes nos seus processos de aprendizagem e uma maior sintonia entre o currículo escolar e as exigências da vida em sociedade. Ainda assim, identifica-se uma mudança no tom desse 
deslocamento dos conhecimentos em relação às competências, dos PCNs à BNCC, de modo a reduzir os conhecimentos a conceitos a serem apreendidos, cabendo ao professor implementar propostas didático-pedagógicas, mas não dialogar com normas e práticas que constituem os modos epistêmicos da área que ensina. Estes aspectos serão aprofundados na continuidade das análises na pesquisa em andamento.

Do cenário desenhado a partir dos excertos dos PCNs e da BNCC, identifica-se como permanência, do ponto de vista do discurso regulador, o reconhecimento da primazia da aprendizagem sobre o ensino, com o que isso supõe de cuidado em relação ao reconhecimento das diferenças entre os estudantes, no que se refere aos seus interesses e às suas necessidades. Entretanto, se a centralidade da aprendizagem nos PCNs apontava para um professor capaz de fazer escolhas de conteúdo e forma a fim de apoiar a construção de sentido para o que se aprende e a participação crítica no mundo, na BNCC isso remete a um professor em busca de caminhos metodológicos diversificados que resultem em bons desempenhos dos estudantes, em grandes avaliações, supõe-se. Ele não "precisa" se preocupar com as escolhas de conteúdo - a BNCC já o fez -, precisa encontrar um meio de aprimorar sua performance e a de seus alunos.

É interessante refletir sobre essas permanências, e especialmente sobre o "apagamento" da figura do professor na BNCC, tendo em vista os desdobramentos da homologação deste documento em normativas subsequentes, bem como nas análises no campo acadêmico.

Assim, em dezembro de 2019, o Conselho Nacional de Educação institui a Resolução $\mathrm{CNE} / \mathrm{CP} \mathrm{n}^{\circ} 2$, que define as Diretrizes Curriculares Nacionais para a Formação Inicial de Professores para a Educação Básica e institui a Base Nacional Comum para a Formação Inicial de Professores da Educação Básica (BNC-Formação). Nessa Resolução no 2 de 2019 assume-se, em seus Artigos $2^{\circ}$ e $3^{\circ}$, que:

Artigo $2^{\circ} \mathrm{A}$ formação docente pressupõe o desenvolvimento, pelo licenciando, das competências gerais previstas na BNCC-Educação Básica, bem como das aprendizagens essenciais a serem garantidas aos estudantes, quanto aos aspectos intelectual, físico, cultural, social e emocional de sua formação, tendo como perspectiva o desenvolvimento pleno das pessoas, visando à Educação Integral

Art. $3^{\circ}$ Com base nos mesmos princípios das competências gerais estabelecidas pela BNCC, é requerido do licenciando o desenvolvimento das correspondentes competências gerais docentes. Parágrafo único. As competências gerais docentes, bem como as competências específicas e as habilidades correspondentes a elas, indicadas no Anexo que integra esta Resolução, compõem a BNC-Formação.

Esses artigos indicam que a formação inicial dos professores que atuarão na educação básica deve assumir como metas formativas aquilo que a BNCC estabelece para a formação dos estudantes, nomeando-as como "competências gerais docentes" - o que na prática significa um pequeno ajuste de termos, mantendo-se essencialmente as mesmas competências gerais da BNCC. Em outras palavras, associa-se o processo de tornar-se competente como professor ao processo de tornar-se competente como estudante - o que sugere que o exemplo do professor será espelhado pelo estudante e torna bastante inespecífico o que vem a ser o conjunto de saberes docentes mobilizados na prática pedagógica. Nessa perspectiva, um professor que "cumpra" estritamente o que prevê a BNCC como aprendizagens essenciais é o modelo que se busca.

Chamamos também a atenção para o fato de que não se discute o caráter provisório que, em nosso entendimento, marca qualquer prescrição curricular, pela sua própria natureza transitória. Ao atrelar a formação do professor aos ditames da BNCC, assume-se a perenidade do documento. E, mais do que isso, assume-se uma suposta infalibilidade do documento frente aos contextos sociais e históricos presente e futuro.

Ao detalhar a estrutura dos cursos de licenciatura, a Resolução nº 2 de 2019 estabelece, no Artigo 11:

Art. 11. A referida carga horária dos cursos de licenciatura deve ter a seguinte distribuição:

I - Grupo I: 800 (oitocentas) horas, para a base comum que compreende os conhecimentos científicos, educacionais e pedagógicos e fundamentam a educação e suas articulações com os sistemas, as escolas e as práticas educacionais. 
II - Grupo II: 1.600 (mil e seiscentas) horas, para a aprendizagem dos conteúdos específicos das áreas, componentes, unidades temáticas e objetos de conhecimento da BNCC, e para o domínio pedagógico desses conteúdos.

III - Grupo III: 800 (oitocentas) horas, prática pedagógica, assim distribuídas:

a) 400 (quatrocentas) horas para o estágio supervisionado, em situação real de trabalho em escola, segundo o Projeto Pedagógico do Curso (PPC) da instituição formadora; e b) 400 (quatrocentas) horas para a prática dos componentes curriculares dos Grupos I e II, distribuídas ao longo do curso, desde o seu início, segundo o PPC da instituição formadora.

Destacamos, nessa distribuição da carga horária dos cursos, que o Grupo II concentra o dobro de horas em relação aos outros dois, sendo que se trata justamente das horas destinadas ao estudo da BNCC, bem como para o desenvolvimento do "domínio pedagógico" de seus conteúdos. Pela centralidade assumida na BNC-Formação para o Grupo II, entre outros aspectos, vai se explicitando o modelo de professor almejado pela política educacional atual: um profissional conhecedor das definições legais da BNCC e pronto para desenvolver as metodologias inovadoras e capazes de mobilizar o interesse dos estudantes e até mesmo de dar significado ao que aprendem.

Em contraponto a essa perspectiva, Leite et al. (2018) remetem à Resolução CNE/CP n 2 de 2015, que define as Diretrizes Curriculares Nacionais para a formação inicial em nível superior (cursos de licenciatura, cursos de formação pedagógica para graduados e cursos de segunda licenciatura) e para a formação continuada. Os autores afirmam que essa Resolução enfatiza a complexidade do trabalho docente, colocando em xeque a ideia de que bastaria a obediência às definições legais para o desenvolvimento de um trabalho escolar de qualidade:

o processo de ensinar, bem como a ação educativa implícita no exercício da profissão do professor, não se restringe a um grupo homogêneo de estudantes organizados em um nível único de ensino, afinal, o professor é formado para atuar na educação básica em diferentes níveis, que possuem especificidades distintas. Além do mais, há de se considerar que, mesmo em turmas de uma mesma categorização, há alunos com diferentes experiências de vida e, portanto, com conhecimentos distintos e que devem ser considerados no processo de ensino-aprendizagem. Outras particularidades e especificidades ainda precisam ser valorizadas, como o fato de haver alunos com deficiências e que, portanto, necessitam também de um atendimento de acordo com suas demandas cognitivas e físicas. (LEITE et al., 2018, p.727)

É importante destacar que, apesar de ainda não se ter sequer tempo suficiente para avaliar o quanto a Resolução $n^{\circ} 2$ de 2015 trouxe mudanças significativas aos cursos de licenciatura, a Resolução $\mathrm{CNE} / \mathrm{CP} \mathrm{n}^{\circ} 2$ de 2019 opera um brusco movimento de retrocesso nas políticas de formação docente no Brasil, como já se afirma no campo acadêmico (RODRIGUES, PEREIRA e MOHR, 2020; GUEDES, 2019; TAFFAREL, 2020).

Fuza e Miranda (2020) também se referem à articulação da BNCC com políticas de formação docente. Elas destacam que, nos períodos iniciais de implementação da BNCC, a revisão da formação inicial e continuada de professores constitui uma tarefa essencial a ser assumida pela União. Mobilizando diversas pesquisas, as autoras apontam que as discussões sobre a BNCC estão relacionadas às questões de poder envolvidas nas decisões sobre a formação e a identidade docente, e constatam que o documento propõe a formação de modelos específicos de estudantes e professores. De acordo com Szundy (2017, p. 85, apud Fuza e Miranda, 2000), ainda destacam que a BNCC:

\footnotetext{
se propõe a englobar a formação do aluno e do professor como sujeitos atuantes em seus contextos. A existência da BNCC não é garantia de que seus pressupostos serão realmente efetivados na escola, pois, além dela, é preciso que haja o professor, "um/a protagonista central para a manutenção e/ou transformação de currículos. [Logo,] o lançamento de quaisquer diretrizes curriculares acaba por trazer posicionamentos acerca da formação de professores/as para o cerne das discussões”. (FUZA E MIRANDA, 2000, p. 5)
}

Selles (2018) considera que a imagem de professor delineada na BNCC contribui para a precarização de seu trabalho, por conferir o que denomina "atestado de incompetência aos professores" no que tange à gestão de seu próprio trabalho. A autora identifica um silenciamento do professor como autor de sua prática na BNCC, o que se agrava diante da associação direta que o documento faz entre 
qualidade da educação e índices de aprovação nos grandes exames, fomentando o cumprimento de metas e o estabelecimento de ranqueamentos. Sublinha ainda que essa é uma forma mais elaborada de controlar o trabalho de professores, que associa seu próprio sucesso e de seus alunos ao desempenho em sistemas padronizados de avaliação, como se isso pudesse configurar um sistema de certificação.

Somado a esses fatores, Selles, já em 2018, reconhecia no cenário educacional brasileiro contemporâneo ao menos duas frentes privatistas que tensionam e interferem nas ações reformadoras. A primeira delas, com forte base mercadológica, apresenta consenso sobre a precariedade de instalações e insumos da escola pública e busca produzir e vender "soluções" para tais problemas, incluindo materiais e processos formativos que buscam incrementar resultados de avaliações. A segunda frente, com um viés neoconservador, pressiona o Estado para a intervenção sobre o trabalho docente, reclamando que determinados valores morais e religiosos, de caráter privado, sejam assumidos como anseios de todos. Embora sejam frentes com interesses e bases ideológicas distintas, a autora ressalta a necessidade de compreendê-las como interesses privatistas articulados para controlar a produção de currículos e a formação docente e que se voltam para todos os níveis de formação, desde a educação básica até o ensino superior (SELLES, 2018).

\section{CONSIDERAÇÕES FINAIS}

Retoma-se, por fim, o que se identificou preliminarmente neste artigo como um aprofundamento do tipo de relação assumida com o conhecimento na escola desde os PCNs, tendo como figura mediadora central o professor, no diálogo com os alunos. Nesse sentido, vale trazer a posição afirmada por Charlot (2008), que nos convida à reflexão sobre os riscos da secundarização do conhecimento escolar frente ao desenvolvimento de competências e à primazia da experiência dos alunos:

A escola é um lugar que requer uma forma de distanciamento para com a experiência cotidiana. O que, nesta, é situação vivenciada e contextualizada, objeto do meio ambiente, torna-se, na escola, objeto de pensamento, de discurso, de texto. Ademais, a escola fala aos alunos de objetos que não se encontram no mundo cotidiano deles e, às vezes, em nenhum mundo sensível e levaos para universos que apenas existem no pensamento e na linguagem. Sendo assim, a escola é fundamentalmente um espaço de palavras que possibilitam a objetivação do mundo e o distanciamento para com ele e que abrem janelas para outros espaços e tempos, para o imaginário e o ideal. Além disso, a escola é um lugar onde a própria linguagem vira objeto de linguagem, de segundo nível: na escola, fala-se sobre a fala. (CHARLOT, 2008, p. 30)

Se assumida a função da escola apresentada por Charlot, resta a discutir, portanto, os papéis a serem desenvolvidos, em articulação e parceria, por professores e alunos na (re)construção de conhecimentos operada no processo curricular, considerando-se aí a força que terão as políticas curriculares atuais sobre a organização das escolas e do trabalho dos professores e alunos.

De forma ainda preliminar, conclui-se que, dos PCNs à BNCC, opera-se um reposicionamento dos modelos de professor e de aluno projetados nos documentos de referência curricular, de modo a desassociar de suas funções no processo pedagógico os dois sujeitos que se constituem na relação didática: quem ensina e quem aprende. Nesse sentido, de um documento a outro, não apenas a agentividade do professor no trabalho pedagógico, prevista nos PCNs, é suprimida na BNCC, mas o próprio trabalho de ensino é representado como um processo independente de um sujeito que o produza e isso já revela mudanças na política de formação inicial e continuada de professores para a educação básica, por exemplo. A desassociação entre ensino e trabalho docente tem sua contraparte, nos documentos em análise, na relação entre aluno e aprendizagem, de modo que esta também seja representada na BNCC como um processo independente do sujeito que aprende.

Se na discussão dos achados deste estudo já se fez menção à BNC-Formação, evidenciando o seu atrelamento à BNCC, o Parecer CNE/CP 14/2020, que institui as Diretrizes Curriculares Nacionais para a Formação Continuada de Professores da Educação Básica e Base Nacional Comum para a Formação Continuada de Professores da Educação Básica (BNC-Formação Continuada), reafirma essa característica. Nesse Parecer, afirma-se que: 
a BNCC demanda que o professor domine, para além dos conhecimentos específicos das diferentes áreas, pedagogias ativas e contextualizadas que facilitem a aprendizagem dos conteúdos curriculares em situações favoráveis ao desenvolvimento das competências sócio emocionais, ao desenvolvimento integral e ao projeto de vida dos estudantes.

Nessa afirmação, sublinha-se o que se espera do professor - que domine os conhecimentos específicos das áreas, o que remete especialmente ao domínio das prescrições expressas na BNCC, e, sobretudo, que seja capaz de desenvolver metodologias ativas e contextualizadas que favoreçam a aprendizagem. O trecho a seguir, do mesmo documento reforça essa ideia, quando diz que

\begin{abstract}
para garantir que os programas destinados à formação de professores resultem em melhoria da prática profissional, é necessário que eles sejam baseados não apenas em conteúdos específicos do currículo escolar, mas também em como ensinar esses conteúdos em seu contexto de atuação, possibilitando ao docente que aprenda a desenvolver estratégias variadas para atingir este fim.
\end{abstract}

Por outro lado, ao tratar dos alunos, o referido Parecer coloca como horizonte formativo o desenvolvimento de competências socioemocionais, o desenvolvimento integral - perspectiva amplamente defendida, que enfatiza a importância de uma formação que vá além da dimensão cognitiva, o que resulta frequentemente em práticas que negam o trabalho com o conhecimento dos componentes, em nome de iniciativas "inovadoras" - e os seus projetos de vida. Dilui-se nesse desenho a importância das relações com o conhecimento escolar e o necessário engajamento dos alunos com seus processos de aprendizagem. Da parte do professor, restringe-se sua relação com o conhecimento específico dos componentes curriculares àquilo que está definido na BNCC, objeto central dos seus estudos, tanto na formação inicial quanto na continuada, segundo as políticas educacionais mais recentes.

Claro que não se está considerando que os modelos de professor e aluno definidos no discurso regulador operam como fatores que determinarão o posicionamento assumido por esses sujeitos no exercício de seu trabalho. O que se salienta é que por esses caminhos discursivos vão se abrindo vias para a produção de outras políticas - como a de formação inicial e continuada de professores ou de produção e distribuição de materiais didáticos - que têm potencial para criar condições materiais e simbólicas muito desfavoráveis para o desenvolvimento de uma educação de qualidade nas escolas brasileiras.

\title{
REFERÊNCIAS
}

BARRETTO, Elba S. S. (Org.). Os currículos do ensino fundamental para as escolas brasileiras. $2^{a}$ ed. Campinas, SP: Autores Associados; São Paulo: Fundação Carlos Chagas, 2000.

BARRETTO, Elba S. S. Políticas de currículo e avaliação e políticas docentes. Cadernos de Pesquisa, v. 42, n. 147, p. 738-753, set./dez. 2012.

BERNSTEIN, Basil. A estruturação do discurso pedagógico. Petrópolis: Vozes, 1996.

BERNSTEIN, Basil. Pedagogy, symbolic control and identity. Theory, research. critique. London: Taylor \& Francis, 2000.

BRANCO, Emerson P., BRANCO, Alessandra B. G., IWASSE, Lilian F. A., ZANATTA, Shalimar C. BNCC: a quem interessa o ensino de competências e habilidades? Debate em Educação, Maceió, v. $11, \quad$ n. $25, \quad$ p. 155-171, 2019. Disponível em: https://www.seer.ufal.br/index.php/debateseducacao/article/view/7505. Acesso em: 20/01/2021. 
BRASIL. Secretaria de Educação Fundamental. Parâmetros curriculares nacionais: introdução aos parâmetros curriculares nacionais. Secretaria de Educação Fundamental. Brasília: MEC/SEF, 1997. BRASIL. Ministério da Educação. Conselho Nacional de Educação. Resolução no 2 , de $\mathbf{1}^{\mathbf{0}}$ de julho de 2015. Brasília: CNE/CP. Disponível em: http://portal.mec.gov.br/docman/agosto-2017pdf/70431-res-cne-cp-002-03072015-pdf/file. Acesso em: 20 jan. 2021.

BRASIL. Ministério da Educação. Secretaria de Educação Básica. Base Nacional Comum Curricular (BNCC). Brasília: MEC, 2017.

BRASIL. Ministério da Educação. Conselho Nacional de Educação. Resolução no 2, de 20 de dezembro de 2019. Brasília: CNE/CP. Disponível em: ttp://portal.mec.gov.br/index.php?option=com_docman\&view=download\&alias=135951-rcp00219\&category_slug=dezembro-2019-pdf\&Itemid=30192. Acesso em: 20 jan. 2021.

BRASIL. Ministério da Educação. Conselho Nacional de Educação. Parecer n⿳0 14, de 10 de julho de 2020. Brasília: CNE/CP. Disponível em: http://portal.mec.gov.br/index.php?option=com_docman\&view=download\&alias=153571-pcp01420\&category_slug=agosto-2020-pdf\&Itemid=30192. Acesso em 20 jan. 2021.

CÁSSIO, Fernando L. Base Nacional Comum Curricular: ponto de saturação e retrocesso na educação. Revista Retratos da Escola, Brasília, v. 12, 2018. Disponível em: http://retratosdaescola.emnuvens.com.br/rde/article/view/887/pdf. Acesso em: 14 jan. 2021.

CHARLOT, Bernard. O professor na sociedade contemporânea: Um trabalhador da contradição. Revista da FAEEBA. Salvador, vol. 17, n. 30, p. 17-31, jul./dez. 2008. Disponível em: http://www.adventista.edu.br/_imagens/asped/files/O\%20professor\%20na\%20sociedade\%20conte mporanea,\%20um\%20trabalhodor\%20da\%20contradic\%C3\%A3o.pdf. Acesso em: 20 jan. 2021. COELHO, Franciele B. de O. Análise de currículos de ciências à luz da teoria de Bernstein. Ciênc. educ., Bauru , v. 23, n. 3, p. 795-808, Jul. 2017. Disponível em: https://www.scielo.br/scielo.php?pid=S1516-73132017000300795\&script=sci_abstract\&tlng=pt. Acesso em: 20/01/2021.

FRANGELLA, Rita de Cássia, DIAS, Rosanne. Os sentidos de docência na BNCC: efeitos para o currículo da educação básica e da formação/atuação de professores. Educação Unisinos, São Leopoldo, v. 22,

n. $1, \quad$ p. 7-15, jan./mar. 2018. Disponível em: http://revistas.unisinos.br/index.php/educacao/article/view/edu.2018.221.01. Acesso em: 20/01/2021. 
FUZA, Ângela F., MIRANDA, Flávia D. S. S. Tecnologias digitais, letramentos e gêneros discursivos nas diferentes áreas da BNCC: reflexos nos anos finais do ensino fundamental e na formação de professores. Rev. Bras. Educ., Rio de Janeiro, v. 25, e250009, 2020. Disponível em: http://www.scielo.br/scielo.php?script=sci_arttext\&pid=S1413-

24782020000100207\&lng=en\&nrm=iso . Acesso em: 12/09/2020.

GALIAN, Cláudia V. A. Os PCN e a produção de propostas curriculares no Brasil. Cadernos de Pesquisa, São Paulo, v. 44, n. 153, p. 648-669, jul./set. 2014. Disponível em: https://www.scielo.br/pdf/cp/v44n153/a09v44n153.pdf. Acesso em: 20 jan. 2021.

GALIAN, Cláudia V. A., SILVA, Roberto R. D. Apontamentos para uma avaliação de currículos no Brasil: a BNCC em questão. Estud. Aval. Educ., São Paulo, vol. 30, n. 74, p. 508-535, mai./ago. 2019. Disponível em: http://publicacoes.fcc.org.br//index.php/eae/article/view/5693. Acesso em: 20 jan. 2021.

GALIAN, Cláudia V. A., STEFENON, Daniel L. Por que é tão difícil definer o conhecimento a ser ensinado na escola? Um olhar para a Geografia. Educação e Filosofia, Uberlândia, v. 32, n. 64, p. 59-90, jan./abr. 2018. Disponível em: http://www.seer.ufu.br/index.php/EducacaoFilosofia/article/view/40442. Acesso em: 20 jan. 2021.

GUEDES, Marilde Q. A Nova Política de Formação de Professores no Brasil: Enquadramentos da Base Nacional Comum Curricular e do Programa de Residência Pedagógica. Invest. Práticas, Lisboa, vol. 9, n. 1, p. $90 \quad-\quad 99$, 2019. Disponível em: http://www.scielo.mec.pt/scielo.php?script=sci_arttext\&pid=S2182-13722019000100009. Acesso em: 20 jan. 2021.

HOADLEY, Ursula. Pedagogy in Poverty. Lessons from Twenty Years of Curriculum Reform in South Africa. London, New York: Routledge, 2018.

HYPOLITO, Álvaro M. BNCC, Agenda Global e Formação Docente. Revista Retratos da Escola, Brasília, v. 13, n. 25, p. 187-201, jan./mai. 2019. Disponível em: http://retratosdaescola.emnuvens.com.br/rde/article/view/995. Acesso em: 15 jan. 2021.

LEITE, Eliana A. P., RIBEIRO, Émerson S., LEITE, Kécio G., ULIANA, Márcia Rosa. Formação de profissionais da educação. Alguns desafios e demandas da formação inicial de professores na contemporaneidade. Educ. Soc., Campinas, vol. 39, n. 144, p. 721-737, jul.-set., 2018. Disponível em: https://www.scielo.br/pdf/es/v39n144/1678-4626-es-es0101-73302018183273.pdf. Acesso em: 20 jan. 2021.

MACIEL, Cilene M. A., NASCIMENTO, Gilvania C., FERNANDES, Cleonice T., KFOURI, Samira F. Visão de professores de escolas de Cuiabá/MT e Campo Verde/MT sobre a Base Nacional Comum 
Curricular (BNCC). Revista de Educação Pública, Cuiabá, v. 26, n. 62, p. 657-673, maio/ago. 2017. Disponível em: https://periodicoscientificos.ufmt.br/ojs/index.php/educacaopublica/article/view/5506/3628. Acesso em: 15 jan. 2021.

MAINARDES, Jefferson, STREMEL, Silvana. A teoria de Basil Bernstein e algumas de suas contribuições para as pesquisas sobre políticas educacionais e curriculares. Revista Teias, Rio de Janeiro, vol. 11, n. 22, p. 31-54, mai./ago. 2010. Disponível em: https://www.epublicacoes.uerj.br/index.php/revistateias/article/view/24114/17092. Acesso em: 20 jan. 2021.

MAINGUENEAU, Dominique. Novas Tendências em Análise do Discurso. Tradução de Freda Indursky. Campinas, SP: Editora Pontes, Editora da Unicamp, 1997.

MAINGUENEAU, Dominique. Gênese dos discursos. Tradução de Sírio Possenti. Curitiba: Criar, 2005.

MANFRÉ, Ademir H. Base Nacional Comum Curricular e (semi) formação: quais os dilemas da escola atual? Revista Espaço do Currículo (online), João Pessoa, v.13, n. Especial, p. 935-945, dez. 2020.

Disponível

em:

https://www.revistas.unijui.edu.br/index.php/contextoeducacao/article/view/9373. Acesso em: 15 jan. 2021.

MORAIS, Ana Maria, NEVES, Isabel P., FERREIRA, Sílvia. O currículo nas suas dimensões estrutural e interacional: Perspetiva de Basil Bernstein. Práxis Educativa, Ponta Grossa, v. 14, n. 2 , mai./ago/ 2019, p. 405-431. Disponível em: https://revistas2.uepg.br/index.php/praxiseducativa/article/view/13265/209209210683. Acesso em: 20 jan. 2021.

NEVES, Isabel P. MORAIS, Ana Maria. Texts and Contexts in Educational Systems: studies of recontextualizing spaces. In: MORAIS, Ana Maria, NEVES, Isabel P., DAVIES, Brian, DANIELS, Harry. (Eds.) Towards a Sociology of Pedagogy. The contribution of Basil Bernstein to research. New York: Peter Lang, 2010, p. 223-250.

RODRIGUES, Larissa Z., PEREIRA, Beatriz, MOHR, Adriana O Documento "Proposta para Base Nacional Comum da Formação de Professores da Educação Básica” (BNCFP): Dez razões para temer e contestar a BNCFP. Revista Brasileira de Pesquisa em Educação em Ciências, Belo Horizonte, vol. 20, p. 1-39, 2020. Disponível em: https://periodicos.ufmg.br/index.php/rbpec/article/view/16205/15250. Cesso em: 15 jan. 2021. SAMPAIO, Maria das Mercês F. Um gosto amargo de escola: relações entre currículo, ensino e fracasso escolar. São Paulo: EDUC, 1998. 
SAMPAIO, Maria das Mercês F., FALSARELlA, Ana Maria, MENDES, M. F. V. A produção intelectual de crítica aos Parâmetros Curriculares Nacionais para o Ensino Fundamental. In: II Colóquio luso-brasileiro sobre questões curriculares, e VI Colóquio sobre questões curriculares, 6. Rio de Janeiro. Currículo: pensar, inventar, diferir, v. 1. Rio de Janeiro: UERJ, 2004. p. 1-10.

SELLES, Sandra E. A BNCC e a Resolução CNE/CP n. ${ }^{\circ}$ 2/2015 para a formação docente: a "carroça na frente dos bois". Caderno Brasileiro de Ensino de Física, Florianópolis, v. 35, n. 2, p. 337-344, ago. 2018. Disponível em: https://periodicos.ufsc.br/index.php/fisica/article/view/21757941.2018v35n2p337/37457. Acesso em: 15/01/2021.

SILVA, Francisco C. Na base, como os professores veem a Base? Sobre currículos e BNCC. Textura, Canoas, v. 22, n. 50, p. 99-117, abr/jun. 2020. Disponível em: http://www.periodicos.ulbra.br/index.php/txra/article/view/5474/3718. Acesso em: 15/01/2021.

SOUSA, Joana Dark A.; ARAGÃO, Wilson H. A concepção de currículo nacional comum no PNE: problematizações a partir do paradigma Neoliberal. Revista Espaço do Currículo (online), João Pessoa, v.11, n.1, p. 3-13, jan./abr. 2018. Disponível em: https://periodicos.ufpb.br/index.php/rec/article/view/ufpb.1983-1579.2018v1n11.39794/32653. Acesso em: 15/01/2021.

TAFFAREL, Celi M. Z. Base Nacional Comum para Formação de Professores da Educação Básica (BNC-Formação): Ocultar, silenciar, inverter para o capital dominar. Nota técnica ANFOPE, dez. 2020. Disponível em: <http://www.anfope.org.br/wp-content/uploads/2019/11/BNCF-CeliTaffarel-24112019.pdf>. Acesso em: 12/09/2020.

WEELAHAN, Leesa. Why knowledge matters in curriculum. A social realist argument. London: Routledge, 2010. 